\title{
Modulation of sensory nerve activity and pharmaceutical treatments
}

\begin{abstract}
Painful peripheral neuropathies related to cellular injury from diverse injury sources including metabolic, drug related, hereditary, malignant carcinomas, infective or postinfective immune responses can unbalance physiological homeostasis. The International Association for the Study of Pain coined the phrase Neuropathic pain to describe, "Pain initiated or caused by a primary lesion or dysfunction in the nervous system". Attenuation of neuropathic remains challenging because it may be caused as well as may be progressed from myriad neuropathic dysfunctions in conjunction with dysfunctional remodeling due to physiologic plasticity. The adoption of advanced multiple strategies in coordination results in mediated transmigration of cells remains paramount to utilizing physiologic plasticity to return homeostatic cellular potentials. The usefulness of implementing current therapies effectively utilizes new research on Toll like Receptor (TLR) Pathways, which conduct interactions between nervous, innate and adaptive immune responses. Targeted application of therapies inhibiting inflammatory pain processing may potentiate or attenuate signaling interactions associated with preservation of cellular, tissue, and systemic rescue.
\end{abstract}

Volume I Issue 2 - 2014

\author{
Marco Sartori, ${ }^{1-4}$ Sonya Day, ${ }^{\prime}$ Mirella \\ Zancato, ${ }^{3}$ Pasquale Piccini,' Claudio Ronco ${ }^{1,2}$ \\ 'Department of Pharmacology, International Renal Research \\ Institute of Vicenza (IRRIV), Italy \\ ${ }^{2}$ Department of Nephrology, St. Bortolo Hospital, Italy \\ ${ }^{3}$ Department of Pharmaceutical and Pharmacological Science, \\ University of Padua, Italy \\ ${ }^{4}$ Department of Molecular Medicine, University of Padua, Italy
}

Correspondence: Sonya Day, Department of Pharmacology, International Renal Research Institute of Vicenza (IRRIV), 37, Viale Rodolfi, 36100,Vicenza, Italy, Email giassara.day@gmail.com

Received: May 27, 2014| Published: June 19,2014

Keywords: Neuropathies, Hypersensitivity, Glycoproteins, Hyperalgesia, Homeostasis, Cytokines

Abbreviations: TLR, Toll Like Receptor; PRRS, PatternRecognition Receptors; PAMPs, Pathogen-Associated Molecular Patterns; TIR, Toll-Interleukin-1 Resistance; CNS, Central Nervous System; BIVA, Bioelectric Vector Analysis; NEMO, NF-kB Essential Modulator; TIRAP, TIR Adaptor Protein; ROS, Reactive Oxygen Species; RNS, Reactive Nitrogen Species; NOS, Reactive Nitrogen Species; SMAC, Second Mitochondria-Derived Activator of Caspase

\section{Introduction}

Direct and indirect injury to nerve systems symptomatically identified as neuropathic pain are known to affect millions of people. ${ }^{1}$ Remarkable progress has been made in the last decade improving our understanding of immune mediation, inflammation and induction of cytokines that highlight structure-activity relationships. Peripheral and central nerve injury activates immune modulators as well as migration of macrophages, which mediate neuropathic pain. ${ }^{2}$ The negative sensory signs that indicate damage to central processes indicate decreased activation threshold and increased membrane excitability. ${ }^{3}$ Rapid publication of research in neuropathic pain and mechanisms aids clinical effectiveness, patient outcomes, as well as development of therapeutic targets. Somato-sensory abnormalities including hyposensitivity and hypersensitivity underlie mechanisms that commonly are too frequently not communicated to or may be easily overlooked by treating physicians. ${ }^{4}$

Utilization of traditional approaches that correlated structural features with the activity of compounds has highlighted the role of signaling intermediaries and trans-membrane pattern recognition receptors in persistent pain states. Although widely recognized for their role in tissue injury and host defense Toll-like receptors (TLRs) are trans membrane pattern-recognition receptors (PRRS) which recognize bacterial lipopolysaccharide and viral double-stranded RNA, and pathogen-associated molecular patterns (PAMPs) from various microorganisms, including bacteria, viruses, protozoa and fungi. The engagement and subsequent molecular cellular responses are differentially expressed in cells and targeted by diverse agents. The TLR family receptor ligand interactions are known to tighten Tollinterleukin-1 resistance (TIR) domains resulting in conformational change and activation of adaptor protein recruitment. While debate continued for many years, the role that that PRRs play in response to injury, clearance of apoptotic-cell debris, and repair of damaged tissues has been substantiated by a mounting body of evidence from in vitro and in vivo studies. Emerging is a novel perspective for examining the etiology of overactive immune mediated responses of exogenous and endogenous ligands by the innate immune system. Current targets for infection and cancer have focused on TLR7 and TLR9 as targets, ${ }^{5}$ while TLR2, TLR4, TLR7 and TLR9 hold promise for treatment of inflammatory diseases and sepsis. ${ }^{6}$ The promise of novel therapeutics targeting receptor structure-activity relationships is based on a wide body of research that has elucidated TLR regulation of innate immune system mediated signaling of multiple gateways and contingent biochemical cascades taken as a whole Current understanding highlights, the overall impact of TLR activity and importance in optimizing therapeutic targets and treatments.

Evidence that return to cellular homeostasis is not a passive process. Attenuation of local chemical mediators and mediation of active mechanisms involved in inflammation resolution have been identified as import targets. ${ }^{7}$ Early identification of subjective negative sensory signs and objective biomarkers has great momentum in the treatment of peripheral neuropathies. Combinatorial approaches while widely used and acknowledged in some clinical settings remain undervalued in others. Amassing research in animal and clinical studies in neuropathic pain treatment demonstrates highly specific regulation and response by proinflammatory and pro-resolution mediators. ${ }^{8}$ The elucidation of TLR pathways has highlighted the extrapolative role of humoral and cellular cross talk underlying pathogenic states likely causative contributors to negative patient outcomes. Microglial activation, independent of stromal macrophage activity in perivascular locations are capable of varied phenotypic and 
dynamic responses including untreatable pathological pain reactions post peripheral nerve injury. ${ }^{9}$ Recent research that spinal glial TLR4 mediated nociception up regulates prostaglandins E (2) and TNF10 and $\mathrm{TLR}^{9}$ has been linked to induction of apoptosis in primed microglia, ${ }^{11}$ highlights the relevance of TLR mediated pathways in the field of pain research.

\section{Therapeutic options and targeting TLRs}

One common problem in medical treatment is the inherent complexity of medications that have demonstrated multiple modes of action. This can be exemplified by both nor-epinephrine and serotonin reuptake inhibitors such as duloxetine and venlafaxine which have analgesic effects independent of antidepressant effects Pharmacokinetic interactions in complicated critical care scenarios, which require combinatorial treatments and may contribute to the release of signaling and effector molecules such as chemokine, cytokines, prostaglandins, and changes to the blood brain barrier. Optimal therapeutic application in the clinical setting includes targeting the positive feedback loop that begins with TLR activation and involves complex signaling cascades responsible for clinical features. Early identification of antagonists and agonists to different TLRs has been advanced by evidence that TLRs and their signaling molecules are associated both with susceptibility and human disease progression. Recognizing the inherent complexity of evaluating pharmacokinetic interactions inherent in therapeutic modulation of sensory nerve activity, remarkable progress has been made. Recent studies have confirmed the clinical significance of TLR agonist and antagonist modulation of patient immune responses at a cellular and behavioral level. Investigations of the abnormal pain hypersensitivity have highlighted the significance of TLRs mediated innate immunity and regulation of neuropathic pain. ${ }^{12}$ TLR and signaling intermediaries have been implicated in persistent pain states including mono neuropathic allodynia. ${ }^{13,14}$ Potent adjuvancity of TLR agonists and antagonists with diverse activity profiles are being designed, developed, and tested for specific immuno-modulatory effects. Blocking specific downstream signaling pathways depends on targeted TLR receptor specific mediation of the inflammatory response. A promising new approach involves micro-RNAs that have cell and or tissue specific expression. Drug discovery may be enhanced by the identification and utilization of micro-RNAs that are negative regulators of TLR signaling. This potential approach exploits micro-RNA cell type specific activity in the modulation of sensory nerve activity. Agonists may offer specific and altered primary and anamnestic immune properties. Immuno-stimulatory selectivity such as Imidazoquinoline derivatives are among TLR agonists that are producing interesting results. Insight into pleiotropic effects of drugs that interact with TLRs has come from studies looking at side effects and immune profiling of toll-like receptor ligands. ${ }^{15}$ While evaluating the complex signaling mechanisms are recognized to have an increasingly valued role in critical care medicine. The signals that dictate cell, tissue, and neuropathic pain state and fate are conveyed by peripheral immune activation and afferent nerve transmission to the brain and peripheral tissues. Imiquimod a known agonist of TLR7 induced IL-6 and TNF alpha is currently used to treat various infectious skin diseases. Imiquimod acts through TLR7-MYD88 dependent pathway, putatively enhances excitability of dorsal root ganglion neurons.

Proliferation of migratory and injury triggered responses by innate immune activation are recognized deleterious agents in disease. Early and late-phase attenuation of neuropathic pain requires tapping the directionality in patients requires transcytotic mediation with tolerogenic activation. Key insights into the pleomorphic effects of statins including the reduction of contrast-induced nephropathy have highlighted the clinical importance of these critical, dynamic, and bidirectional capabilities inherent in TLRs.

The distinction of neuropathic and nociceptive pain from other pain types may not be well understood by family, patients, and hospital caregivers, although rapid communication of symptomatic and etiological observations are likely to assist the treating physician. The distinct and overlapping roles of immune and nervous system responses to acute injury share important underlying mechanisms. Looking at combined traditional and novel combinations that are patient specific may yet enhance necessary steps to state-of-the-art deployment of biomarkers and therapeutic techniques. Goal oriented application may simultaneously attenuate multi-symptomatic responses by reducing oxidative stress, inflammation and apoptotic responses.

Recent options for neuropathic pain have entered the pharmacologic setting although remain underutilized. The prescribing trends over the past decade have focused on opioids for symptomatic treatment This clinical practice remains controversial due to concerns that this type of pain therapy does not always respond well to these agents as well as the well recognized potential for adverse effects and addiction. ${ }^{16,17}$ Opioids remain the gold standard for treatment of severe acute and chronic pain. Opioids exert their potent analgesic properties via classical opioids receptors but they can also induce a pro-inflammatory response within the central nervous system (CNS). The primary cell type initiating such pro-inflammatory responses is likely microglia, the predominant immunocompetent cell within the CNS. These cells have been implicated in chronic pain and dysregulating the effects of opioids. ${ }^{18}$ Therefore, we need novel target molecules that may lead to the development of promising analgesics drugs like high-mobility group box 1 (HMGB1 $)^{19}$ and new compounds necessary have to taste as in a case Palmitoylethanolamide. ${ }^{20}$ Moreover, treatment with opioids can induce hyperalgesia in humans and animals, and activation of Toll-like receptor 4 (TLR4) ${ }^{21}$ has been proposed to induce such hyperalgesia. Furthermore other routes exist resulting hyper activation of glial and non-neuronal cells. ${ }^{22}$ When recommendations trends remain pent within old medications (Table 1) several deleterious consequences result.

\section{Diagnostic challenges and options}

The role TLRs play in mediating and attenuating inflammation and has been widely expanded during the last decade. Initiation and maintenance of chronic pain can no longer be considered without the contribution of TLR-induced proinflammatory cytokines. Specifically TLR4 up regulation by sensitized microglia is being further investigated to mechanisms in the transition from acute to chronic pain. ${ }^{23}$ Early investigations revealed the critical role of cytokines in CNS development and function. The complex nature which enables the detection of danger-associated molecular patterns (DAMPs) and pathogen-associated molecular patterns (PAMPs) by TLRs is of paramount importance to considering the TRIF and MyD88 intracellular signaling cascades that mediate the production of pro- and anti-inflammatory cytokines. The term inflammasome describes the molecular mechanisms that play a role in pathological pain following TLR activation. ${ }^{24}$ More recent investigations have focused on how these receptors so critical to CNS development and function may be activated to contribute to the resolution of inflammation specifically neuro protection and remyelination. 
Table I Common medications used in treating neuropathic pain as a first and second line

\begin{tabular}{|c|c|c|}
\hline Medications & Mechanism of Action & Major Side Effects \\
\hline \multicolumn{3}{|l|}{ First Line Medications } \\
\hline $\begin{array}{l}\text { Tricyclic } \\
\text { Antidepressant } \\
\text { (TCA)* } \\
\text { (Secondary amine } \\
\text { compounds) } \\
\text { Nortriptyline } \\
\text { Desipramine }\end{array}$ & $\begin{array}{l}\text { They are reuptake inhibitors of the biogenic } \\
\text { amines NE as well as } 5 \mathrm{HT} \text { by different selectivity: } \\
\text { - } \quad \text { secondary amine NE }>5-\mathrm{HT} \\
\text { tertiary amine } 5-\mathrm{HT}>\mathrm{NE}\end{array}$ & $\begin{array}{l}\text { Anti-cholinergic adverse effects are commonly (dry mouth, } \\
\text { orthostatic hypotension, constipation, urinary retention). } \\
\text { Cardiac toxicity has to be evaluated. }\end{array}$ \\
\hline $\begin{array}{l}\text { Selective Serotonin } \\
\text { Norepinephrine } \\
\text { Reuptake Inhibitor } \\
\text { (SSNRI) } \\
\text { Duloxetine, Venlafaxine }\end{array}$ & $\begin{array}{l}\text { They are a reuptake inhibitor of the biogenic } \\
\text { amines NE, } 5 H T \text { and DA:5-HT, NE>DA reuptake } \\
\text { inhibition }\end{array}$ & $\begin{array}{l}\text { The most common adverse effect of Duloxetine is nausea } \\
\text { but does not seem to have cardiac toxicity or blood pressure } \\
\text { variations observed for Venlafaxine. }\end{array}$ \\
\hline $\begin{array}{l}\text { Calcium Channel } \boldsymbol{\alpha}_{\mathbf{2}}-\boldsymbol{\delta} \\
\text { Ligands } \\
\text { Gabapentin } \\
\text { Pregabalin }\end{array}$ & $\begin{array}{l}\text { They are ligands of voltage-gated calcium channels } \\
\text { at } \alpha_{2}-\delta \text { subunit, so they inhibit neurotransmitter } \\
\text { release. }\end{array}$ & $\begin{array}{l}\text { The major side effects of both are dosage dependent dizziness } \\
\text { and sedation. Patient individualized dosage adjustments for renal } \\
\text { insufficiency are an important consideration. }\end{array}$ \\
\hline $\begin{array}{l}\text { Anesthetic** } \\
5 \% \text { Lidocaine patch }\end{array}$ & It is a $\mathrm{Na}^{+}$channel blocker. & $\begin{array}{l}\text { Applied as a topical treatment without systemic adsorption } \\
\text { is an important advantage in critical care. The most common } \\
\text { adverse effects are mild local reactions and Immunologic allergic } \\
\text { systemic reactions to lidocaine are very rare from topical } \\
\text { application. }\end{array}$ \\
\hline Second Line Medications_ & & \\
\hline $\begin{array}{l}\text { Opioid Agonists } \\
\text { Morphine } \\
\text { Oxycodone } \\
\text { Methadone } \\
\text { Levorphanol }\end{array}$ & $\begin{array}{l}\text { Morphine and related } \mu \text {-agonist opioids produce } \\
\text { their major effects by acting as agonists, major } \\
\text { interactions occurring at } \mu \text {-receptor. It remains } \\
\text { a lesser-known but important consideration that } \\
\text { they also have appreciable variable affinity for } \delta \\
\text { and } \kappa \text { receptors. }\end{array}$ & $\begin{array}{l}\text { Well-known salient considerations of opioid use are patient } \\
\text { tolerance, and physical dependence. Side effects include: } \\
\text { respiratory depression, constipation, nausea, dizziness or } \\
\text { vertigo, somnolence, drowsiness, vomiting, dry skin, itching, } \\
\text { pruritus, urinary retention, myoclonus, dysphoria, euphoria, } \\
\text { sleep disturbance, sexual dysfunction, inappropriate secretion of } \\
\text { vasopressin, and dry mouth. }\end{array}$ \\
\hline $\begin{array}{l}\text { Opioid Agonists } \\
\text { Tramadol }\end{array}$ & $\begin{array}{l}\text { Tramadol's major action is as a } \mu \text {-agonist with } \\
\text { concomitant inhibition of } 5-\mathrm{HT} \text { and NE reuptake. }\end{array}$ & $\begin{array}{l}\text { Frequently documented side effects include nausea, dizziness } \\
\text { following from constipation, dry mouth, vomiting and other } \\
\text { typical side effects of opioid agonist. Critical care priority } \\
\text { utilization is based on evidence that tramadol has relatively low } \\
\text { abuse potential and side effects. }\end{array}$ \\
\hline
\end{tabular}

NE, nor epinephrine; Serotonin, 5HT; DA, dopamine

*TCA tertiary amine is a second choice when secondary amine compounds are not available

**Only for Topical treatment

A surprisingly simple component to oxidative stress, inflammatory response, and apoptotic tissue damage plagues critical care settings in the first world as much as others in some cases. Hydration status seriously contributes to patient outcomes, hospital costs, and mortality. Optimal fluid management in the critical care clinical setting is beleaguered by multiple issues including assessment time, type of assessment tool, reliability, accuracy, and the amount and type of therapeutic interventions given to the patient. Variations in hydration due to fluid therapy in critically ill patients represent a core a precipitating mechanism of accurate prognosis and patient outcomes. The pathobiology resultant from patient hyper-hydration states has pleiotropic negative consequences involving metabolic, cell signaling, and disruption of receptor-mediated mechanisms of tissue protection. ${ }^{25} \mathrm{New}$ techniques applying vector analysis to populations may increase our capability of regulating key changes in a variety of clinically relevant mediation of pain as well as pathophysiology. In organ failure cytokine signaling and modulation may warn of secondary organ failure following initial cardiac or kidney insult and even assist in early acute injury detection. ${ }^{26}$ These considerations are particularly relevant in critical care settings where a constellation of change in pharmacokinetic and pharmacodynamics (PK/PD) parameters can occur in patients so there is an intrinsic difficulty to adjust the dosage of single analgesic drug, furthermore $\mathrm{PK} / \mathrm{PD}$ negative interactions should be considered and eventually extracorporeal therapy such as kidney and liver support. Bioelectrical Impedance Vector Analysis (BIVA) can be used for hydration status assessment. ${ }^{27}$ Recent evidence supports the use of Specific BIVA in the clinical setting. ${ }^{28}$ Bioelectrical impedance has been used in diverse methods, and vector analysis applied to impedance measurements has been used with increasing frequency for the last two decades in the critical care arena. Bioelectric Vector Analysis (BIVA) combines with bioimpedance measures of capacity produced by the interfaces of tissues and cell membranes generating an output that reflects simultaneously abnormal changes in soft tissue mass and hydration status. The concomitant positive effects of diagnostic based therapy application which is patient specific assists physiologic functions of absorption, reducing exacerbation of inflammatory tissue responses, regulation of purine nucleotide metabolite secretion including adenosine which have been implicated chloride secretion ${ }^{29}$ and changes in surface expression and polarization of epithelial cells. ${ }^{30}$ Accurate patient hydration status assessment, with specific attention to patient hydration state prior to adjuvant therapy accomplishes a coordinated series of clinically advantageous events simultaneously. 
The hydration status and concentration of secondary metabolites and small signaling molecules appear to modulate killing signaling, and thus the ability for interventional tactics to have far-reaching effects. In addition to the practical implementation being increasingly adopted of using specific BIVA assessments to augment traditional fluid balance assessment there are new approaches to investigate the signaling cascade. Many of these molecules have a range of properties with demonstrated ion, protein, or lipid binding. In addition to accurate hydration assessment novel techniques such as the Lixelle Column are being developed as alternatives and enable exploration of previously mentioned functions. Critically it is known understood that both immune cell mediated and bacterial signaling communication molecules exhibit multiple properties. These properties include regulatory protein interaction, alteration in gene expression, resource sequestration, membrane intercalation, all of which vitally contribute to patient recovery. This approach signals a new extracorporeal technology to augment goal pharmacological treatments in the clinical setting.

The role of early detection with biomarkers in the critical care setting is enhanced significantly due to the last decade of research. In either necrotic or apoptotic cytokine induced cell death has pleiotropic effects including alteration of Fast expression and inducible form cell nitric oxide synthase (iNOS) expression. Resolution to neuropathic pain as well as myriad comorbidities requires intervention aimed at deterring if not attenuating these pathogenic cell and tissue state changes. Biomarkers that are key components of proinflammatory signaling must also meet criteria requisite for broad spread applicability in the clinical setting: the biomarker expression must be conserved across many patient populations in diverse phases of pathology, expressed levels must be temporally related to the inciting stimulus as in response to infection, the levels expressed of the protein assayed from the bio fluids must be an accurate reflection of patient response, the protein must be stable and rapidly decay during resolution of the episode. Some Glycoproteins commonly used as blood-based biomarkers play a major role in the body's defense as components of the cell membrane and as antigenic determinants.

The pro-inflammatory damage response to alter metabolic and catabolic activities alike when, unmitigated by behaviors that may alter and promote healing, but what is appearing to be a return to a balanced cascade of molecular targeting molecules including metal proteases. ${ }^{31}$ Great new research on resolvins as analgesics to target unrelenting injury stimulus cascades in response to prolonged CNS activation and astrocyte up regulation of proinflammatory factors is an exciting and encouraging approach. ${ }^{32}$ The distinct roles of matrix metal proteases have been implicated in both early and latephase development of neuropathic pain. ${ }^{33}$ Lipocalins are a family of Glycoproteins that have emerged with considerable interest both because of their small size, relative stability, and critical role in pathologic states. ${ }^{34} \mathrm{~A}$ key target of clinical interest in this family is NGAL, a small $25-\mathrm{kDa}$ lipocalin normally expressed in low levels in vivo by cardiomyocytes, lymphocytes, and renal tubular cells. These well-researched interactions are increased by orders of magnitude in response to further injurious stimuli. NGAL, otherwise known as siderocalin, lipocalin- $2,{ }^{35}$ uterocalin, and $24 \mathrm{p} 3$ is induced in bacterial infection, attenuating pericellular as well as cellular labile iron by sequestering bacterial iron chelators. ${ }^{36}$ NGAL is readily assayed in wide variety of pathologies including diagnosis of infection. ${ }^{37}$ The developing research indicates a widespread utility from Alzheimer's to Acute Kidney injury. ${ }^{38}$ Understanding these biomarkers biochemical communicative properties will inevitably advance targeted application and adjustment for patients.

\section{Nociceptor Sensitization Properties of Cells}

A chronic and prolonged period of stressor signaling produces tissue damage and neuronal sensitization. ${ }^{39}$ Importantly one of the key aspects of leukocyte recruitment to sties of inflammation is nociceptor sensitization. ${ }^{40}$ TNF-alpha release during the immune responses and inflammatory disease states has been shown along with other soluble mediators to induce sensitizations of peripheral nociceptors. ${ }^{41}$ Neuropathic pain questionnaires, DN4, and other technologies exist to identify and classify pain qualities even by non-specialists. Early identification by analyzing patients' individual symptoms represents a perhaps undervalued aspect to determine individualized treatment regimes. An approach that enables clinician indicated advanced assessment and diagnostics which so fundamental to mechanismbased treatment approaches.

The balancing act of our signaling effects to Toll like Receptors has wide targets, and works well to predicate successful attack against bacterial, viral and cancerous cells trying to acquisition metal ions, and cellular circuitry required for organ and organism function. Primary insult, such as, a wound, or genetic and environmental factors result in oxidative stress and alterations in pro-inflammatory signaling which work well in the aforementioned case, but become dangerous under prolonged fight or flight signaling. A key target investigated as a putative modulator of insulin signaling is serine phosphorylation of insulin receptor substrate (IRS)-1. ${ }^{42}$ Nitric Oxide (NO) is involved in blood pressure regulation, and protection against pathogens..$^{43}$ One characteristic of this "batten down the hatches" proinflammatory release is that a variety of chemo preventative enhancing treatments are widely demonstrated. ${ }^{44}$ Signaling buffering with chemo preventative approaches is well explored in cancer research. ${ }^{45}$ Failure to attenuate cellular responses to initial pathology unremittingly leads to negative outcomes in some cases specifically exacerbated by contributive mitochondrial dysfunction. Mitochondrial dysfunction well known to be fundamental to insulin resistance, obesity, and diabetes, has negative metabolic consequences with far reaching effects. Proinflammatory chemical mediators related to diverse sources of initial injury have from a signaling perspective important shared systemic and biochemical consequences. Initial injury from a growing number of identified sources, including but not limited to, metabolic, drug related, hereditary, malignant carcinomas, infective or post-infective immune responses require active rather than passive intervention. Specifically limiting participation of apoptotic leukocytes and reducing soluble bioactive mediators as in the lowing proinflammatory chemokine signaling may have large-scale concomitant positive effects for active counter-regulation. For example etiological alterations in insulin metabolic signaling putatively associated with insulin resistance from mitochondrial dysfunction have been demonstrated by gene expression studies and gene array analysis showing clear expression alteration of mitochondrial ATP production. ${ }^{46}$ Mitochondrial dysfunction profoundly alters insulin signaling compromising glucose-stimulated pancreatic insulin secretion as well as skeletal muscle insulin-stimulated glucose utilization.

The reduction-oxidation (redox) equilibrium of cells and tissues is critical to the inflammatory state of tissues, and it is well recognized that changes by injurious signaling can lead to a proinflammatory state. Increased proinflammatory cytokines such as TNF-alpha, IL-1B, IL-6, and ROS-generating enzymes are known to have downstream effects such as NF-kB activator (TANK) interaction with NF-kB essential modulator (NEMO) indicating a chain of events that lead to bridging My D88-dependent and MyD88 independent pathways. Critical to understanding the chain of events are Toll like Receptors 
(TLRs). TLR 4 specifically is known to potentiate the MyD88 dependent pathway utilizing the TIR domain-containing adaptor protein (TIRAP) critically triggering NF-kB activation and My D88 independent pathways.

\section{Cell fate altering properties of reactive nitrogen and oxygen species}

ROS's Simple small molecules including superoxide, hydroxyl, alkoxyl, and peroxyl which are oxygen radicals, and non-radicals like hydrogen peroxide $\left(\mathrm{H}_{2} \mathrm{O}_{2}\right)$ which can be neutralized by antioxidants, or metabolized respectively in the optimal milieu of cellular homeostasis. Loss of redox homeostasis results in proliferative effects from reactive oxygen species (ROS) and reactive nitrogen species (RNS). This propagates proinflammatory signaling and a profribrotic feedback loop. ${ }^{47}$ Reactive Oxygen Species and pro-inflammatory signaling as well as normal adaptive immune response exquisitely execute cell, tissue and human organizational capacity at its prime. Importantly the hydrostatic, pharmacokinetic interactions resultant in cytokine cascade changes implicates induced cell death mechanisms in both necrosis and apoptosis. The bidirectional capability inherent in the TLR family ${ }^{48}$ towards or away from tolerance as well as activation of inflammatory positive feedback loops offers significant promise in novel therapeutic application as well as evaluation of successful combinatorial therapeutic approaches.

Limiting risks of comorbidity warrants attention to patient medical history and resolution cues, initially established in animal models the immune mediated contributions to neuropathic induced alterations have elucidated signaling mechanisms that underlie chronic pain and inflammation.49 Medical treatments that have secondary implications influence TLR pathways by nitric oxide synthase inducible (iNOS) and Fast expression putatively exacerbating pathways contributive to neuropathic pain. ${ }^{50}$ The crosstalk required for inhibition of inflammatory pain processing has highlighted the role of signaling pathways and immuno histochemical changes ${ }^{51}$ additionally prompting investigation into many new drugs, approaches, and potent adjuvanticity of some traditional treatment options. Reactive oxygen species and nitrogen species (RONS) are of current clinical and therapeutic interest for their modulation of important signaling pathways and concomitant pleiotropic physiological responses. ${ }^{52}$ Chemokine involvement in inflammation, angiogenesis, hematopoiesis, and embryonic development are known to be exerted through G-protein-coupled receptors. ${ }^{53}$ Growing evidence suggests that generation in excess of reactive oxygen species (ROS) and concomitant oxidative stress influences pathogenesis of neurodegenerative disorders beyond the well-known oxidation of biological macromolecules. Furthermore considering optimal targeting of these independent and interactive pathways can benefit current application in the clinical setting. Release of endogenous TLR7 and TLR9 ligands by environmental modifications including oxidative damage which can exacerbate sensitization and deregulation common in mice and patients can exacerbate the overall impact of TLR activity. The contributive myriad effects of degenerative medical scenarios such as myocardial infarction, ischemia and reperfusion remain incompletely understood. Immune mediated interactions and their pathology in single and dual organ failure patients may hold a key to unraveling the complex puzzle. Transcytotic mediation and alteration of cellular tolerogenic response are known to contribute to perpetuation by increasing the sensitivity of target cells and up regulation of Toll-like receptor signaling adapter proteins. ${ }^{54}$ High levels of Reactive oxygen species (ROS) and Reactive nitrogen species (NOS) as well as increasing unremitting signaling from long recognized pro-inflammatory cytokine and chemokine molecular signals results in cascading the effects of those same initial protective signals. Prolonged molecular pressure from molecular signals to alter cell function may result in imbalance between oxidants and antioxidants; commonly called oxidative stress potentially leads to cell injury. ${ }^{55}$ TLR mediated dysfunction leading to secondary TLR dependent cell activation such as second mitochondria-derived activator of caspase (SMAC) induction of cell apoptosis via cytochrome-c-dependent cell activation. SMAC as well as multiple concomitant affects may manifest decreasing therapeutic efficacy. It is well known statins functionally reduce endothelin that is elevated in atherosclerosis and a known marker of endothelial injury including increasing Nitric oxide bioavailability. ${ }^{56}$ The putative ability to mediate decreased expression of endothelial adhesion molecules ICAM-1 and VCAM- 157 and their anti-oxidative properties when used in combinatorial therapeutic application may prove more efficacious. This is substantiated by evidence indicating that HMG-CoA reductase inhibitors decrease vascular superoxide generation. ${ }^{58}$ Recently published data has demonstrated the protective effect on renal tubular cells in contrast induced nephropathy using short-term, high-dose pretreatment. ${ }^{59}$ Consideration and continued clinical case studies are needed to augment understanding and application of research mechanisms at play. Timely publication and access to results of combinatorial therapeutic approaches, which may vary significantly from animal models and research models, will continue optimization of therapeutic applications in the clinical setting.

Cellular signals indicate cells to engage in alterations which when lack counter balance result in programming changes both temporal and epigenetic. It is well known that negative patient outcomes increase dramatically in a milieu of immune mediated monocyte phenotype transition, myocyte apoptosis. ${ }^{60}$ Using the plethora of studies that contribute to our mechanistic understanding exposes symptoms, which like oxidative stress are harmful, and have demonstrated responses in a variety of studies over the last decades. ${ }^{61}$ In an extreme way terminological confusion may add to difficult clinical scenarios. New terms like neuro inflammation are intentional descriptors of communal pathologies, are not necessarily indicative of molecular mechanistic differences. At a biochemical level molecules are named with different motives and even a quick examination of signaling targets with demonstrated relevance in microglial activation indicates the problematic potential for academic disagreement; Toll-like receptor 4 (TLR4), purinergic receptor P2X, ligand-gated ion channel 4, interferon-gamma, monocyte chemo attractant protein- 1 and others. ${ }^{62}$ The ontological status of medical terminology for spontaneous and acute injury remains a stalwart impediment to brilliant advances and innovative approaches used successfully. Academic disagreements threaten to obscure a plethora of great research, and herculean efforts by physicians and researchers. Reducing the noise of the latter will continue as increasing numbers of dedicated physicians monitor patient state changes and administration of traditional therapies.

The lack of precise pharmaceutical targeting of biological mechanisms represents a limit to clinical effectiveness, and moreover has the clinical consequence of increased variability of drug response among patients that poses a major limiting factor in clinical practice (Table 2).

\section{Discussion}

Recent progress in multiple fields has indicated complex activation of alternative pathways with potential implications for optimizing therapeutic options in the clinical setting. The mechanisms by which 
induction of innate and adaptive immune response lead to apoptotic cell death in discrete and distant cell populations have significant socio economic repercussions both directly and indirectly. Therapeutic treatment may be significantly optimized by reflection on untargeted elicitation of primary and anamnestic immune responses by TLR engagement. Activation TLRs resulting in co-stimulatory signals and powerful extensive structure-activity relationships between both agonists and antagonists of TLR engagement can be further exploited to control up regulation of pro-inflammatory cytokines and clonal expansion. The extensive involvement of lymphocytes, neutrophils, monocytes, platelets, mast cells, astrocytes have been associated with the initiation of symptoms as well as perpetuation by contributing to both regulatory pathways and inflammatory processes. Rapid communication highlighting the key TLRs and their relevant pathways would likely expand existing knowledge about
TLR mediated downstream cascades including peripheral and central glial activation, spinal sensitization, NF-kB dependent cytokine production and NF-kB independent interferon induction in respect to pharmacokinetic properties of existing drugs. A panacea such as the development of a single target protein is unlikely to achieve therapeutic target effects due to the complexity inherent in multiple interacting cascades. Encouragingly pragmatic approaches directed at related to unwanted TLR activation of innate immune effector mechanisms, up regulation of proinflammatory cytokines mediated by immunological and neuronal cellular responses remain a prominent option for reduction in pathological consequences and high mortality rates in clinical treatment. The question of pace may be advanced by empirical data that evaluate efficacy and symptomatic resolution indicating clinical results from pragmatic approaches followed by peer reviewed rapid publication of empirical evidence.

Table 2 Third line medications and novel treatment options

\begin{tabular}{|c|c|c|}
\hline Medications & Mechanism of Action & Major Side Effects \\
\hline \multicolumn{3}{|l|}{ First Line Medications } \\
\hline $\begin{array}{l}\text { Tricyclic } \\
\text { Antidepressant } \\
\text { (TCA)* } \\
\text { (Secondary amine } \\
\text { compounds) } \\
\text { Nortriptyline } \\
\text { Desipramine }\end{array}$ & $\begin{array}{l}\text { They are reuptake inhibitors of the biogenic } \\
\text { amines NE as well as } 5 \mathrm{HT} \text { by different selectivity: } \\
\text { - } \quad \text { secondary amine } \mathrm{NE}>5-\mathrm{HT} \\
\text { tertiary amine } 5-\mathrm{HT}>\mathrm{NE}\end{array}$ & $\begin{array}{l}\text { Anti-cholinergic adverse effects are commonly (dry mouth, } \\
\text { orthostatic hypotension, constipation, urinary retention). } \\
\text { Cardiac toxicity has to be evaluated. }\end{array}$ \\
\hline $\begin{array}{l}\text { Selective Serotonin } \\
\text { Norepinephrine } \\
\text { Reuptake Inhibitor } \\
\text { (SSNRI) } \\
\text { Duloxetine, } \\
\text { Venlafaxine }\end{array}$ & $\begin{array}{l}\text { They are a reuptake inhibitor of the biogenic } \\
\text { amines NE, } 5 \mathrm{HT} \text { and DA:5-HT, NE>DA reuptake } \\
\text { inhibition }\end{array}$ & $\begin{array}{l}\text { The most common adverse effect of Duloxetine is nausea } \\
\text { but does not seem to have cardiac toxicity or blood pressure } \\
\text { variations observed for Venlafaxine. }\end{array}$ \\
\hline $\begin{array}{l}\text { Calcium Channel } \\
\boldsymbol{\alpha}_{2}-\boldsymbol{\delta} \text { Ligands } \\
\text { Gabapentin } \\
\text { Pregabalin }\end{array}$ & $\begin{array}{l}\text { They are ligands of voltage-gated calcium channels } \\
\text { at } \alpha_{2}-\delta \text { subunit, so they inhibit neurotransmitter } \\
\text { release. }\end{array}$ & $\begin{array}{l}\text { The major side effects of both are dosage dependent dizziness } \\
\text { and sedation. Patient individualized dosage adjustments for renal } \\
\text { insufficiency are an important consideration. }\end{array}$ \\
\hline $\begin{array}{l}\text { Anesthetic** } \\
5 \% \text { Lidocaine patch }\end{array}$ & It is a $\mathrm{Na}^{+}$channel blocker. & $\begin{array}{l}\text { Applied as a topical treatment without systemic adsorption } \\
\text { is an important advantage in critical care. The most common } \\
\text { adverse effects are mild local reactions and Immunologic allergic } \\
\text { systemic reactions to lidocaine are very rare from topical } \\
\text { application. }\end{array}$ \\
\hline \multicolumn{3}{|l|}{$\begin{array}{l}\text { Second Line } \\
\text { Medications_ }\end{array}$} \\
\hline $\begin{array}{l}\text { Opioid Agonists } \\
\text { Morphine } \\
\text { Oxycodone } \\
\text { Methadone } \\
\text { Levorphanol }\end{array}$ & $\begin{array}{l}\text { Morphine and related } \mu \text {-agonist opioids produce } \\
\text { their major effects by acting as agonists, major } \\
\text { interactions occurring at } \mu \text {-receptor. It remains } \\
\text { a lesser-known but important consideration that } \\
\text { they also have appreciable variable affinity for } \delta \\
\text { and } \kappa \text { receptors. }\end{array}$ & $\begin{array}{l}\text { Well-known salient considerations of opioid use are patient } \\
\text { tolerance, and physical dependence. Side effects include: } \\
\text { respiratory depression, constipation, nausea, dizziness or } \\
\text { vertigo, somnolence, drowsiness, vomiting, dry skin, itching, } \\
\text { pruritus, urinary retention, myoclonus, dysphoria, euphoria, } \\
\text { sleep disturbance, sexual dysfunction, inappropriate secretion of } \\
\text { vasopressin, and dry mouth. }\end{array}$ \\
\hline $\begin{array}{l}\text { Opioid Agonists } \\
\text { Tramadol }\end{array}$ & $\begin{array}{l}\text { Tramadol's major action is as a } \mu \text {-agonist with } \\
\text { concomitant inhibition of } 5-\mathrm{HT} \text { and NE reuptake. }\end{array}$ & $\begin{array}{l}\text { Frequently documented side effects include nausea, dizziness } \\
\text { following from constipation, dry mouth, vomiting and other } \\
\text { typical side effects of opioid agonist. Critical care priority } \\
\text { utilization is based on evidence that tramadol has relatively low } \\
\text { abuse potential and side effects. }\end{array}$ \\
\hline
\end{tabular}

Serotonin, $5 \mathrm{HT}$

*The third line medications should be reserved for patients who do not respond to first-and -second line medications and they are active in a subgroup of patients **Only for Topical treatment

Further regulated deviation from tolerance both by patients, care giver and physician evaluation must be considered in optimizing treatment. Long-term potentiating of healing and attenuation of proinflammatory cytokine expression vital require combinatorial existing therapies that are both temporally and kinetically. The duality of signaling pathways continues to acmes the rapid assessment of symptoms in tandem with quantitative clinical assessments. Combinatorial diagnostic approaches may direct clinical attention and 
active intervention to resolve concentration of chemical mediators in local and distant cellular milieus and certainly may continue to be seen as a key principle in understanding pathological mechanisms. ${ }^{63}$ The model approach continues to solicit practical, experimental, and individualized attention to existing options to halt exacerbation of proinflammatory TLR activation and nuclear factor-kB (NF-kB) signaling, obviously responsive and adaptable in the clinical setting. The high cost of unmitigated presynaptic and postsynaptic alterations is known to induce long-term abnormal neural activity along primary afferent pathways. ${ }^{64}$ Early and late-phase attenuation of neuropathic pain requires combinatorial approaches promoting the bidirectional tolerogenic activation by PRRs and early identification of effector mechanisms of inflammation.

\section{Acknowledgments}

None.

\section{Conflicts of Interset}

None.

\section{References}

1. Bouhassira D, Lanteri-Minet M, Attal N, et al. Prevalence of chronic pain with neuropathic characteristics in the general population. Pain. 2008;136(3):380-387.

2. Saab CY, Waxman SG, Hains BC. Alarm or curse? The pain of neuroinflammation. Brain Res Rev. 2008;58(1):226-235.

3. Baron R. Mechanisms of disease:neuropathic pain-a clinical perspective. Nat Clin Pract Neurol. 2006;2(2):95-106.

4. Haanpaa ML, Backonja MM, Bennett MI, et al. Assessment of neuropathic pain in primary care. Am J Med. 2009;122(10 Suppl):S13S21.

5. Rakoff-Nahoum S, Medzhitov R. Toll-like receptors and cancer. Nat Rev Cancer. 2009;9(1):57-63.

6. O'Neill LA, Bryant CE, Doyle SL.Therapeutic targeting of tolllike receptors for infectious and inflammatory diseases and cancer. Pharmacol Rev. 2009;61(2):177-197.

7. Savill J, Dransfield I, Gregory C, et al. A blast from the past:clearance of apoptotic cells regulates immune responses. Nat Rev Immunol. 2002;2(12):965-975.

8. Rossi AG, Haslett C. Inflamation, cell injury, and apoptosis. In Said SI (Ed.), Proinflammatory and Antiinflammatory Peptides. Marcel Dekker, New York, USA, 1998; pp. 9-24.

9. Biber K, Tsuda M, Tozaki-Saitoh H, et al. Neuronal CCL21 up-regulates microglia P2X4 expression and initiates neuropathic pain development. EMBO J. 2011;30(9):1864-1873.

10. Saito O, Svensson CI, Buczynski MW, et al. Spinal glial TLR4mediated nociception and production of prostaglandin E(2) and TNF. $\mathrm{Br}$ J Pharmacol. 2010;160(7):1754-1764.

11. He L, Li H, Chen L, et al. Toll-like receptor 9 is required for opioidinduced microglia apoptosis. PLoS One. 2011;6(4):e18190.

12. Marchand F, Perretti M, McMahon SB. Role of the immune system in chronic pain. Nat Rev Neurosci. 2005;6(7):521-532.

13. Kim D, Kim MA, Cho IH, et al. A critical role of toll-like receptor 2 in nerve injury-induced spinal cord glial cell activation and pain hypersensitivity. J Biol Chem. 2007;282(20):14975-14983.

14. Kim D, Lee S, Lee SJ. Toll-like receptors in peripheral nerve injury and neuropathic pain. Curr Top Microbiol Immunol. 2009;336:169-186.
15. Hood JD, Warshakoon HJ, Kimbrell MR, et al. Immunoprofiling toll-like receptor ligands Comparison of immunostimulatory and proinflammatory profiles in ex vivo human blood models. Hum Vaccin. 2010;6(4):322-325.

16. McNicol ED, Midbari A, Eisenberg E. Opioids for neuropathic pain Cochrane Database Syst Rev. 2013;8:CD006146.

17. EFIC. Opioid use for persistent pain:a 21 st century perspective, USA, 2013.

18. Hutchinson MR, Bland ST, Johnson KW, et al. Opioid-induced glial activation:mechanisms of activation and implications for opioid analgesia, dependence, and reward. Scientific World Journal. 2007;7:98-111.

19. Maeda T, Ozaki M, Kobayashi Y, et al. HMGB1 as a Potential Therapeutic Target for Neuropathic Pain. J Pharmacol Sci. 2004;123(4):301-305.

20. Esposito G, Capoccia E, Turco F, et al. Palmitoylethanolamide improves colon inflammation through an enteric glia/toll like receptor 4-dependent PPAR- $\alpha$ activation. Gut. 2014;63(8):1300-1312.

21. Cao L, Tanga FY, Deleo JA. The contributing role of CD14 in toll-like receptor 4 dependent neuropathic pain. Neuroscience. 2009;158(2):896-903.

22. Tanga FY, Raghavendra V, DeLeo JA. Quantitative real-time RT- PCR assessment of spinal microglial and astrocytic activation markers in a rat model of neuropathic pain. Neurochem Int. 2004;45(2-3):397-407.

23. Hutchinson MR, Ramos KM, Loram LC, et al. Evidence for a role of heat shock protein-90 in toll like receptor 4 mediated pain enhancement in rats. Neuroscience. 2009;164(4):1821-1832.

24. Hoffman HM, Wanderer AA. Inflammasome and IL-1beta-mediated disorders. Curr Allergy Asthma Rep. 2010;10(4):229-235.

25. Linden J. Molecular approach to adenosine receptors:receptor-mediated mechanisms of tissue protection. Annu Rev Pharmacol Toxicol. 2001;41:775-787.

26. Kashani K, Al-Khafaji A, Thomas A, et al. Discovery and validation of cell cycle arrest biomarkers in human acute kidney injury. Critical Care. 2013;17:R25.

27. Basso F, Berdin G, Virzi GM, et al. Fluid Management in the Intensive Care Unit:Bioelectrical Impedance Vector Analysis as a Tool to Assess Hydration Status and Optimal Fluid Balance in Critically Ill Patients. Blood Purif. 2013;36(3-4):192-199.

28. Buffa R, Saragat B, Cabras S, et al.Accuracy of specific BIVA for the assessment of body composition in the United States population. PLoS One. 2013;8(3):e58533.

29. Madara JL, Patapoff TW, Gillece-Castro B, et al. 5'-Adenosine monophosphate is the neutrophil-derived paracrine factor that elicits chloride secretion from T84 intestinal epithelial cell monolayers. J Clin Invest. 1993;91(5):2320-2325.

30. Strohmeier GR, Lencer WI, Patapoff TW, et al. Surface expression, polarization, and functional significance of CD73 in human intes- tinal epithelia. J Clin Invest. 1997;99(11):2588-2601.

31. Ronco C, House AA, Haapio M. Cardiorenal syndrome:Refining the definition of a complex symbiosis gone wrong. Intensive Care Med. 2008;34(5):957-962.

32. Xu ZZ, Zhang L, Liu T, et al. Resolvins RvE1 and RvD1 attenuate inflammatory pain via central and peripheral actions. Nat Med. 2010;16(5):592-597.

33. Kawasaki Y, Xu ZZ, Wang X, et al. Distinct roles of matrix metalloproteases in the early- and late-phase development of neuropathic pain. Nat Med. 2008;14(3):331-336. 
34. Pedersen KR, Ravn HB, Hjortdal VE, et al. Neutrophil gelatinaseassociated lipocalin (NGAL):validation of commercially available ELISA. Scand J Clin Lab Invest. 2010;70(5):374-382.

35. Hatipoglu S, Sevketoglu E, Gedikbasi A, et al. Urinary MMP-9/ NGAL complex in children with acute cystitis. Pediatr Nephrol. 2011;26(8):1263-1268.

36. Haase M, Bellomo R, Devarajan P, et al. Accuracy of neutrophil gelatinase-associated lipocalin (NGAL) in diagnosis and prognosis in acute kidney injury:a systematic review and meta-analysis. Am J Kidney Dis. 2009;54(6):1012-1024.

37. Naudé PJ, Nyakas C, Eiden LE, et al. Lipocalin 2:novel component of proinflammatory signaling in Alzheimer's disease. FASEB J. 2012;26(7):2811-2823.

38. Martino FK, Filippi I, Giavarina D, et al. Neutrophil gelatinaseassociated lipocalin in the early diagnosis of peritonitis:the case of neutrophil gelatinase-associated lipocalin. Contrib Nephrol. 2012;178:258-263.

39. Capuano A, De Corato A, Lisi L, et al. Proinflammatory-activated trigeminal satellite cells promote neuronal sensitization:relevance for migraine pathology. Mol Pain. 2003;5:43.

40. Sorkin LS, Xiao WH, Wagner R, et al. Tumour necrosis factoralpha induces ectopic activity in nociceptive primary afferent fibres. Neuroscience. 1997;81(1):255-262.

41. Verri WA Jr, Cunha TM, Parada CA, et al. IL-15 mediates immune inflammatory hypernociception by triggering a sequential release of IFN- $\gamma$, endothelin, and prostaglandin. Proc Natl Acad Sci U S A. 2006;103(25):9721-9725.

42. Rosca MG, Hoppel CL. New aspects of impaired mitochondrial function in heart failure. J Bioenerg Biomembr. 2009;41(2):107-112.

43. Alderton WK, Cooper CE, Knowles RG. Nitric oxide synthases:structure, function and inhibition. Biochem J. 2001;357(Pt 3):593-615.

44. Burstein MJ. Dietary factors related to colorectal neoplasms. Surg Clin North Am. 1993;73(1):13-29.

45. Janne PA, Mayer RJ. Chemoprevention of colorectal cancer. $N$ Engl J Med. 2000;342(26):1960-1968.

46. Oh J, Wunsch R, Turzer M, et al. Advanced coronary and carotid arteriopathy in young adults with childhood-onset chronic renal failure. Circulation. 2002;106(1):100-105.

47. Haurani MJ, Pagano PJ. Adventitial fibroblast reactive oxygen species as autocrine and paracrine mediators of remodeling:bellwether for vascular disease? Cardiovasc Res. 2007;75(4):679-689.

48. Ehlers M, Ravetch JV. Opposing effects of Toll-like receptor stimulation induce autoimmunity or tolerance. Trends Immunol. 2007;28(2):74-79.

49. Cao L, DeLeo JA. CNS-infiltrating CD4+ T lymphocytes contribute to murine spinal nerve transection-induced neuropathic pain. Eur $J$ Immunol. 2008;38(2):448-458.
50. Clark AK, Staniland AA, Malcangio M. Fractalkine/CX3CR1 signalling in chronic pain and inflammation. Curr Pharm Biotechnol. 2011;12(10):1707-1714.

51. Ledeboer A, Sloane EM, Milligan ED, et al. Minocycline attenuates mechanical allodynia and proinflammatory cytokine expression in rat models of pain facilitation. Pain. 2005;115(1-2):71-83.

52. Forman HJ, Torres M, Fukuto J. Redox signaling. Mol Cell Biochem. 2002;234-235(1-2):49-62.

53. Oppermann M. Chemokine receptor CCR5:insights into structure, function, and regulation. Cell Signal. 2004;16(11):1201-1210.

54. Kawai T, Akira S. Signaling to NF-kappaB by Toll-like receptors. Trends Mol Med. 2007;13(11):460-469.

55. Sies H. Oxidative stress:Oxidants and antioxidants. Exp Physiol. 1997;82(2):291-295.

56. Hernandez-Perera O, Perez-Sala D, Navarro-Antolin J, et al. Effects of the 3-hydroxy-3-methylglutaryl-CoA reductase inhibitors, atorvastatin and simvastatin, on the expression of endothelin- 1 and endothelial nitric oxide synthase in vascular endothelial cells. J Clin Invest. 1998;101(12):2711-2719.

57. Patti G, Chello M, Pasceri V, et al. Protection from procedural myocardial injury by atorvastatin is associated with lower levels of adhesion molecules after percutaneous coronary intervention:results from the ARMYDA-CAMs (Atorvastatin for Reduction of MYocardial Damage during Angioplasty-Cell Adhesion Molecules) substudy. J Am Coll Cardiology. 2006;48(8):1560-1566.

58. Ritake Y, Kawashima S, Takeshita S, et al. Anti-oxidative properties of fluvastatin, an $\mathrm{HMG}-\mathrm{CoA}$ reductase inhibitor, contribute to the prevention of atherosclerosis in cholesterol-fed rabbits. Atherosclerosis. 2001;154(1):87-96.

59. Patti G, Ricottini I, Nusca A, et al. Short-term, high-dose Atorvastatin pretreatment to prevent contrast-induced nephropathy in patients with acute coronary syndromes undergoing percutaneous coronary intervention (from the ARMYDA-CIN [atorvastatin for reduction of myocardial damage during angioplasty - contrast-induced nephropathy] trial. Am J Cardiol. 2011;108(1):1-7.

60. Virzi GM, Day S, de Cal M, et al. Heart-kidney crosstalk and role of humoral signaling in critical illness. Crit Care. 2014;18(1):201.

61. Felton GW. Oxidative stress of vertebrates and invertebrates. In:Ahmad S (Ed.), Oxidative Stress and Antioxidant Defenses in Biology. Chapman and Hall, New York, USA, 1995; pp. 356-434.

62. Rivest. Regulation of innate immune responses in the brain. Nat Rev Immunol. 2009;9(6):429-439.

63. Majno G, Joris I. Cells, Tissues and Disease:Principles of General Pathology. Oxford University Press, New York, USA, 2004; pp. 1040.

64. Basbaum AI, Bautista DM, Scherrer G, et al. Cellular and molecular mechanisms of pain. Cell. 2009;139(2):267-284. 